\title{
Breast Hamartoma: Mammography and Magnetic Resonance Imaging
}

\section{Biren A Shah*, Fareed Riyaz and Brandon Brockbank}

Virginia Commonwealth University, USA

Submission: October 04, 2017; Published: October 24, 2017

*Corresponding author: Biren A Shah, Virginia Commonwealth University, 1201E Marshall St, Richmond, VA23298, USA,

Email: biren.shah@vcuhealth.org

\begin{abstract}
Hamartoma of the breast is an uncommon benign mass of the breast. This painless, mobile breast mass is typically diagnosed using mammography, with the pathognomonic finding of a "breast within a breast." Additional imagings techniques are used when inconclusive results are found with mammography. This report describes a patient case of a classic hamartoma seen on a screening mammogram and on a breast MRI study.
\end{abstract}

\section{Introduction}

A breast hamartoma is a relatively uncommon, benign, slow growing mass found in women. The incidence of hamartoma of the breast is reported at $0.1-0.7 \%$, but this is likely under diagnosed [1]. Current estimates report an incidence of $1.2 \%$ with increased use of mammography [2].

Pathologically, the hamartoma is a well circumscribed benign mass composed of fat, dense fibrous tissue, and glandular tissue. Clinically, they typically present as round, painless, and mobile breasts lumps [3]. Breast hamartomas are generally found in women older than 35 years of age, with size ranging from $1 \mathrm{~cm}$ to $17 \mathrm{~cm}$ and are presumed to be due to dysgenesis [4]. Most lesions are asymptomatic, and are typically discovered as incidental findings on screening mammography. If a palpable mass is discovered on physical exam, mammography is the preferred method for diagnosis.

\section{Case Presentation}

43 year-old female for a bilateral screening mammogram.
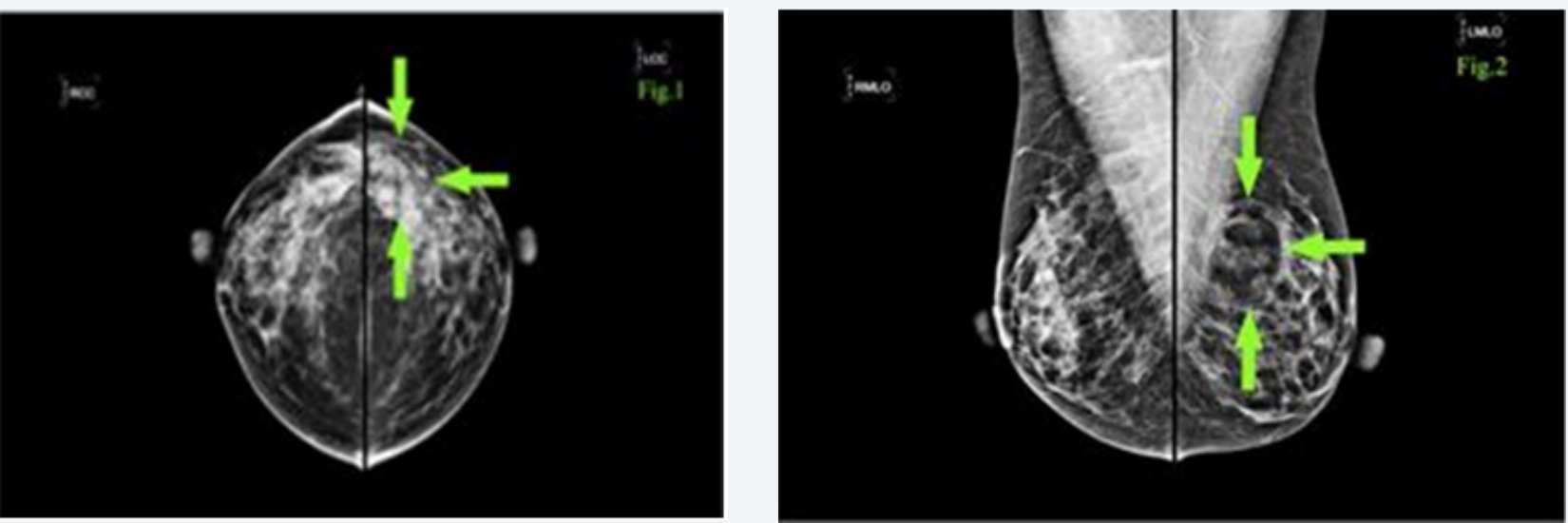

Figure 1 \& 2: Mammogram: MLO (Figure 1) and CC (Figure 2) views of the left breast show a circumscribed oval mass containing fat and fibroglandular tissue at 3-o'clock posteriorly (Figure 3-5) 


\section{Juniper Online Journal of Case Studies}

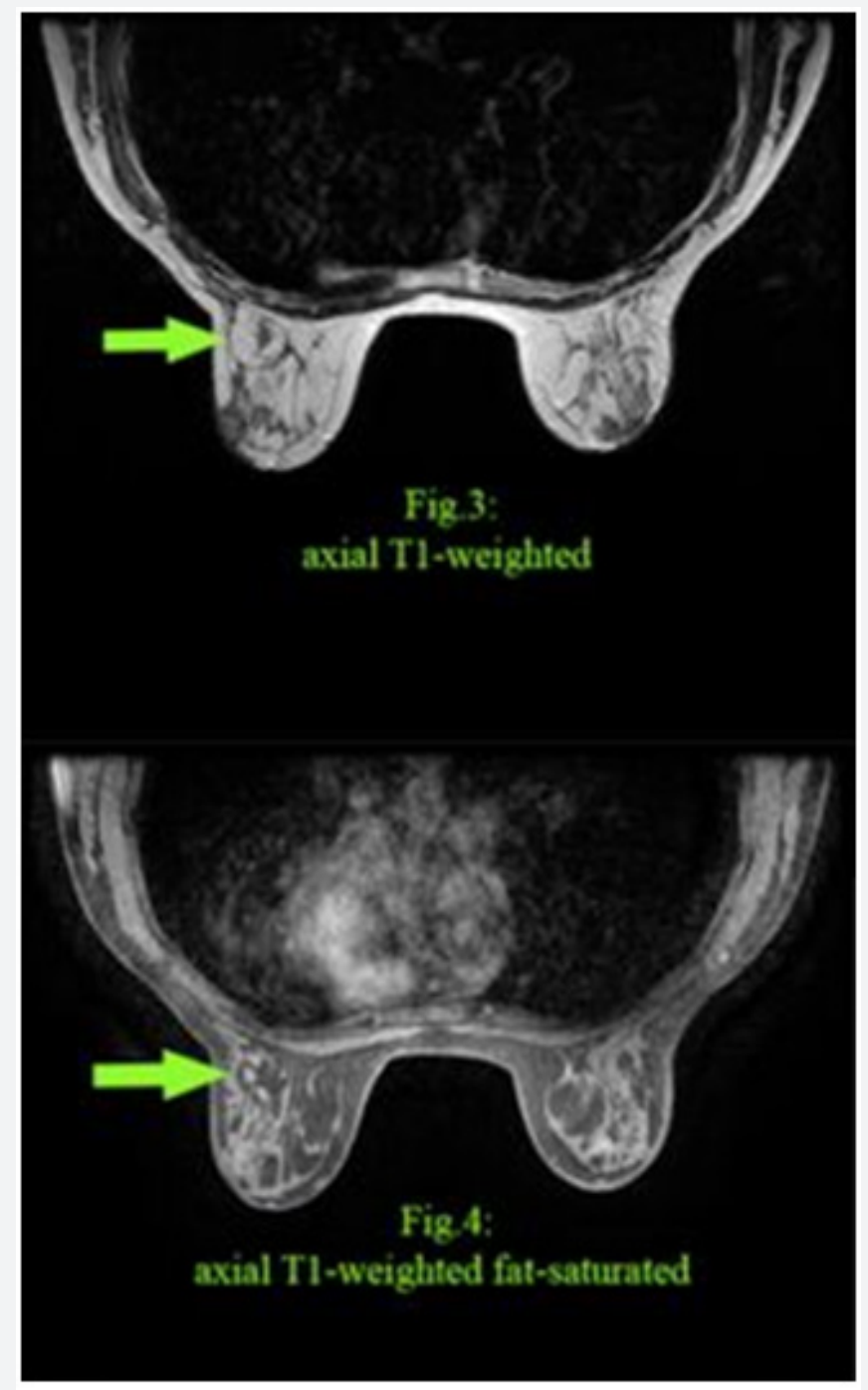

Figure 3 \& 4: MRI: Axial T1-weighted image (Figure 3), axial T1-weighted fat-saturated image (Figure 4) show an oval circumscribed mass at 3-o'clock posteriorly that contains a mixture of fat and glandular tissues. The post-contrast gadolinium images (not shown) demonstrated no enhancement.
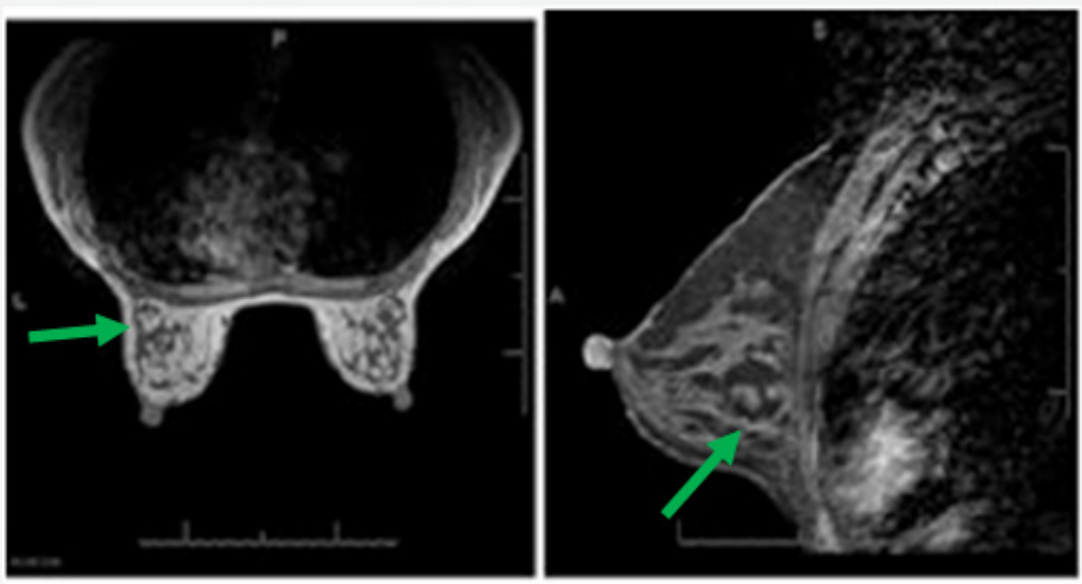

Figure 5 


\section{Discussion}

Hamartoma of the breast was first described by Arrigoni et al. [5] as breast lesions that were well circumscribed and clinically resembled fibroadenoma. Histologically, these lesions showed glandular elements with preserved ducts, lobules, fibrous stroma, and adipose tissue in variable proportions [5]. In 1978, Hessler et al. [6] described the mammography findings of breast hamartoma as a "breast within a breast" because the hamartoma is completely separate from the rest of the breast. It does not replace breast tissue, but instead pushes the inherent breast parenchyma aside [6].

Diagnosis of breast hamartoma typically occurs with mammography, whether during typical screening as an incidental finding, or when indicated by detection of a palpable mass on physical exam.

On mammography, a circumscribed oval or round mass consisting of fat and fibroglandular tissue is highly suggestive of a hamartoma. It has been described as having a "breast within a breast" appearance with lobulated densities comparable to a "slice of salami." Other findings on mammography may include a thin, radiopaque pseudocapsule and benign calcifications.

If the typical mammographic signs are not seen and results are inconclusive, additional diagnostic techniques are recommended. If a lesion contains little fat and demonstrates a dominance of fibrous or fibroglandular elements, fibroadenoma or a well circumscribed carcinoma must be ruled out [7]. Additional imaging that can help in diagnosis of breast hamartoma includes ultrasonography, computed tomography, and core biopsy [8]. Magnetic resonance imaging is not commonly used to diagnose hamartoma of the breast but does have characteristic findings. On MRI, hamartomas are well encapsulated with a dark smooth thin rim, oval or round in shape with internal fat densities and heterogeneity. They do not demonstrate significant gadolinium enhancement. MRI findings can provide diagnostic information in a lactating or pregnant woman in whom mammography is not preferred. Erdemet al. [9] described the MRI appearance of a hamartoma as that of an encapsulated mass with fat and fibroglandular signal intensity. The fibro-glandular elements may exhibit some contrast enhancement. Although these other forms of imaging can be utilized, they are not recommended when the mammography findings demonstrate the typical "breast within a breast," and can even be counterproductive [10].

The characteristic mammographic appearance of a breast hamartoma is pathognomonic and virtually diagnostic. Typically no further follow-up or intervention is required. Excision can be performed if the lesion is symptomatic or if the patient is bothered by the mass. Malignancy with a breast hamartoma is extremely rare and thus aggressive management is not indicated.

\section{References}

1. Fisher CJ, Hanby AM, Robinson L, Millis RR (1992) Mammary hamartoma. A review of 35 cases. Histopathology 20(2): 99-106.

2. Farrokh D, Hashemi J, Ansaripour E (2011) Breast hamartoma: mammographic findings. Iran J Radiol 8(4): 258-260.

3. Lee WF, Sheen-Chen SM, Chi SY, Huang HY, Ko SF (2008) Hamartoma of the breast: an under recognized disease? Tumori 94(1): 114-115.

4. Rosen PP (2001) Rosen's Breast Pathology. In: Rosen PP (Ed.), ( $2^{\text {nd }}$ edn), Lippincott Williams \& Wilkins, Philadelphia, Pennsylvania, USA, p. 779.

5. Arrigoni MG, Dockerty MA, Judd ES (1971) The identification and treatment of mammary hamartomas. Surg Gynecol Obstet 133(4): 577-582.

6. Hessler C, Schnyder P, Ozzello L (1978) Hamartoma of the breast: diagnostic observation of 16 cases. Radiology 126(1): 95-98.

7. Bhatia M, Ravikumar R, Maurya VK, Rai R (2015) "Breast with in a breast" sign: Mammary hamartoma. Med J Armed Forces India 71(4): 377-379.

8. Berna JD, Nieves FJ, Romero T, Arcas I (2001) A multimodality approach to the diagnosis of breast hamartomas with a typical mammographic appearance. Breast J 7(1): 2-7.

9. Erdem G, Karakaş HM, Işık B, Fırat AK (2011) Advanced MRI findings in patients with breast hamartomas. Diagn Interv Radiol 17(1): 33-37.

10. Black J, Metcalf C, Wylie EJ (1996) Ultrasonography of breast hamartomas. Journal of Medical Imaging and Radiation Oncology 40(4): 412-415.

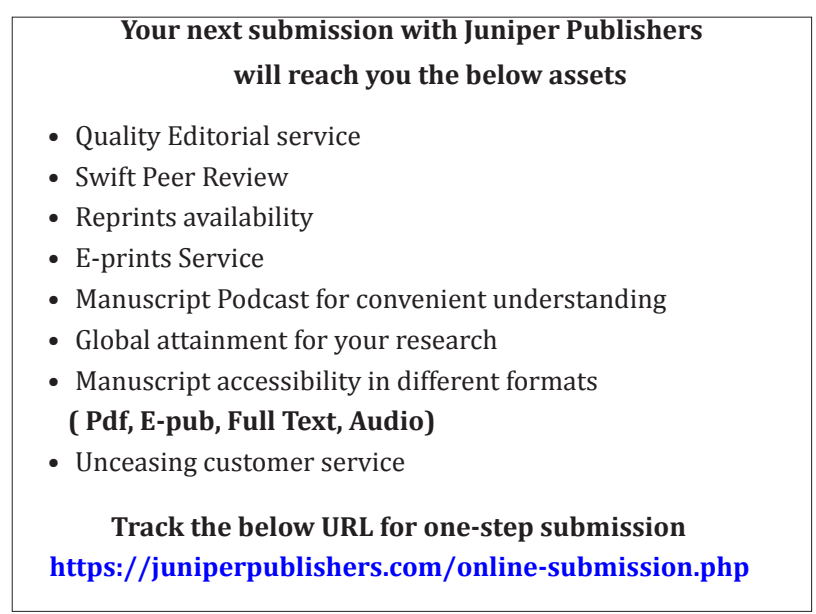

